\title{
Physiotherapy for airway clearance in adults
}

\begin{abstract}
J.A. Pryor
Physiotherapy for airway clearance in adults. J.A. Pryor. (C)ERS Journals Ltd 1999.

ABSTRACT: Techniques for augmenting, when necessary, the normal mucociliary and cough clearance mechanisms of the lungs are not new, but, in more recent years, techniques have been developed which are effective, comfortable and can be used independent of an assistant in the majority of adolescents and adults.

Postural drainage with chest clapping and chest shaking has, in most parts of the world, been replaced by the more effective techniques of the active cycle of breathing, autogenic drainage, R-C Cornet $\mathrm{R}$, Flutter $\mathrm{R}$, positive expiratory pressure mask, highfrequency chest wall oscillation and intrapulmonary percussive ventilation. Glossopharyngeal breathing is being considered again and is often a useful technique for increasing the effectiveness of cough in patients with tetraplegia or neuromuscular disorders.

The evidence in support of these techniques is variable, and the literature is confusing and conflicting. There may or may not be significant differences among the techniques in the short or long term. Many of the regimens now include the forced expiratory manoeuvre of a "huff" and this has probably increased the effectiveness of airway clearance. If objective differences are small, individual preferences and cultural influences may be significant in increasing adherence to treatment and in the selection of an appropriate regimen or regimens for an individual patient.

Eur Respir J 1999; 14: 1418-1424.
\end{abstract}

Dept of Cystic Fibrosis, Royal Brompton \& Harefield NHS Trust, London, UK.

Correspondence: J.A. Pryor

Dept of Cystic Fibrosis

Royal Brompton Hospital

Sydney Street

London SW3 6NP

UK

Fax: 4402073518052

Keywords: Airway clearance physiotherapy

Received: May 51999

Accepted after revision September 301999
In health mucociliary clearance and cough mechanisms are normally effective and efficient, but become overloaded if these systems malfunction and in the presence of excessive bronchial secretions. The majority of work on airway clearance has been undertaken in patients with medical chest problems and extrapolated to the patient with airway clearance problems following surgery. This may be due partly to the difficulty in establishing reproducible baseline values as these are constantly changing in the postoperative patient. The literature is confusing with comparisons between and among regimens making interpretation difficult. Meta-analyses and reviews on airway clearance techniques have been undertaken [1-6], but it has been very difficult to compare like with like as some studies have used the generic name for a technique but used a different technique in practice.

\section{Historical background}

One of the first documented treatments for airway clearance is probably the following, found on an Assyrian tablet. "If the patient suffers from hissing cough, if his wind-pipe is full of murmurs, if he coughs, if he has coughing fits, if he has phlegm: bray together roses and mustard in purified oil, drop it on his tongue, fill, moreover, a tube with it and blow it into his nostrils.
Thereafter he shall drink several times beer of the finest quality; thus he will recover." [7].

Breathing and physical exercise, as accessories to medical and surgical treatment, were described by MACMAHON [8] in 1915. His patients were soldiers with injuries to the lung, pleura and diaphragm. The progress of the patients was described as "remarkable", with improvements in appetite, sleep and general appearance usually seen within 1 week of starting the exercise treatment. The first reference to the use of forced expiration as a breathing exercise may have been that of MACMAHON [8] "the patient breathes in through the nose and the lower ribs are felt to be strongly expanding. The mouth is opened wide and the abdominal muscles slowly and strongly contracted, so that the air is driven from the lungs".

By 1919, "a very large experience of chest cases" had shown "how very important it is that where there is serious lung collapse and chest deformity, following wounds or illness, breathing and physical exercises should, in certain cases, be given as accessories to medical and surgical treatment, if the best possible recovery is to be assured" [9]. This philosophy continues today and is supported by an increasing evidence base.

EwART [10], in 1901, described a technique, "The continuous postural method" for bronchiectasis and chronic bronchial affections. The recommendation was "continuous" drainage but this could be reduced to $1 \mathrm{~h}$ twice or

Previous articles in this Series: No. 1. E. Houtmeyers, R. Gosselink, G. Gayan-Ramirez, M. Decramer. Regulation of mucociliary clearance in health and disease. Eur Respir J 1999; 13: 1177-1188. No. 2. C.P. van der Schans, D.S. Postma, G.H. Koëter, B.K. Rubin. Physiotherapy and bronchial mucus transport. Eur Respir J 1999; 13: 1477-1486. No. 3. E. Houtmeyers, R. Gosselink, G. GayanRamirez, M. Decramer. Effects of drugs on mucus clearance. Eur Respir J 1999; 14: 452-467. No. 4. L. Denehy. The use of manual hyperinflation in airway clearance. Eur Respir $J$ 1999; 14: 958-965. 
three times daily if "continuous" drainage was poorly tolerated. W. Ewart believed that this was "preferable" to the intermittent use of posture, which had previously been recommended by S.H. Quincke in 1898 [10]. Thirty-six years later, "continuous" posturing was still advocated [11] often starting with $10 \mathrm{~min}$ three times a day and gradually increasing to at least three periods of $2 \mathrm{~h}$ during the day and for the greater part of the night. The use of postural drainage with vibration and clapping percussion, in combination with a bronchodilator, was documented in 1953 as more effective than breathing exercises alone in the prevention of postoperative pulmonary atelectasis [12]. Postural drainage with chest clapping remained the "gold standard" of chest physiotherapy for many years, until new techniques emerged in the 1960s [13, 14].

Since then, different airway clearance techniques have developed independently in different parts of the world. Each is claimed to be effective at mucus clearance and to provide independence for the patient. Autogenic drainage (AD) evolved in Belgium and has been modified by the Germans. The active cycle of breathing techniques (ACBT) originated in New Zealand with many of the randomized clinical trials having been undertaken at the Royal Brompton Hospital in the UK. The positive expiratory pressure (PEP) mask was developed in Denmark, high-pressure

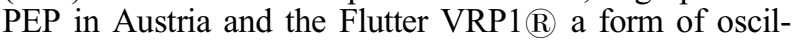
lating PEP in Switzerland. More recently another form of oscillating PEP, the RC-Cornet $\mathbb{R}$, has been developed in Germany. High-frequency chest wall oscillation (HFCWO), intrapulmonary percussive ventilation (IPV) and other mechanical devices, for example incentive spirometry (IS), are widely used in the USA. Glossopharyngeal ("frog") breathing (GPB) was also first documented in the US literature. Exercise is emphasized in the Scandinavian countries together with airway clearance techniques.

Cultural differences, the patient's preference and the patient's knowledge and expectations, the degree of autonomy of the physiotherapist, physical therapist or respiratory therapist, and the availability of evidence in support of one or other of the regimens influence practice and adherence to treatment in different countries. The dominant pathogenic organism, in patients with chronic lung disease, may influence mucus viscosity. Mucus viscosity and disease severity may influence the effectiveness of an airway clearance regimen.

\section{Postural drainage and breathing exercises}

"Conventional" postural drainage is usually understood to be the use of gravity-assisted positions, deep breathing exercises with or without chest clapping, chest shaking or chest vibrations, and coughing when secretions reach the upper airways. Gravity-assisted positioning has been shown to be more effective than cough alone [15] and more effective than the use of either coughing or breathing exercises in the sitting position [16], but these studies refer to patients with excessive bronchial secretions. Gravity-assisted positions will facilitate the clearance of secretions in patients with abnormalities of the cilia, for example primary ciliary dyskinesia [17], and the drainage of secretions from open abscess cavities, but their clinical effectiveness in other conditions is being questioned with the advent of airway clearance techniques and drugs which alter mucus viscosity.
In the surgical patient, breathing exercises are often a part of the postoperative regimen. The paper of JENKINS et al. [18] is often quoted in discussions on breathing exercises in patients following cardiac surgery. They concluded that breathing exercises were not necessary in low-risk patients undergoing cardiac surgery, but huffing, which is a breathing exercise, was part of each of the three regimens. This was acknowledged in a later paper by BouRN and JENKINS [19]. There is evidence that the low-risk patient will benefit from early ambulation and may not need to use additional airway clearance techniques, but this cannot be extrapolated to the high-risk patient or to the patient who develops pulmonary complications [19].

In the postoperative patient, positioning to improve functional residual capacity [20] may be more effective in reducing atelectasis than positioning to effect the drainage of bronchial secretions. Positioning can also be used to improve lung function and the matching of alveolar ventilation to capillary blood flow to different parts of the lung [21]. With some of the techniques used today, for example $\mathrm{AD}$, the PEP mask and the ACBT, positioning the patient to improve airflow to a particular part of the lung may improve airway clearance by allowing air to track behind secretions. The increase in airflow may assist in the mobilization and clearance of secretions.

WARD et al. [22] studied some of the effects of deep breathing: a single deep breath, a deep breath held for $5 \mathrm{~s}$ and multiple deep breaths. They concluded that a deep breath that is held is the most efficient way of reducing atelectasis. The review of TUCKER and JENKINS [23] suggests that the effects of thoracic expansion (deep breathing) exercises probably include increasing lung volumes, facilitating the removal of excess bronchial secretions and aiding the re-expansion of lung tissue.

\section{Percussion and vibration}

Chest clapping (manual chest percussion) and mechanical chest percussion will increase intrathoracic pressure [24], but the relationship between this increase in pressure and airway clearance is yet to be determined.

CAMpBell et al. [25] and Wollmer et al. [26] demonstrated an increase in airflow obstruction when chest clapping was included in an airway clearance regimen, but other studies have not shown any increase $[27,28]$. Chest clapping has also been shown to cause an increase in hypoxaemia [29, 30], but, when short periods of chest clapping $(<30 \mathrm{~s})$ have been combined with three or four thoracic expansion exercises, no fall in oxygen saturation has been seen [31]. Some patients with severe lung disease demonstrate oxygen desaturation with self chest clapping [32]. This may be due to the work of the additional upper limb activity.

In patients with neuromuscular weakness or paralysis and in those who are intellectually impaired, in addition to in infants and in small children, chest clapping or mechanical percussion may be a useful airway clearance technique; coughing is stimulated, possibly by the mobilization of secretions. Manual chest shaking and chest vibrations may augment expiratory flow and may assist in the mobilization of secretions.

GALLON [33] reviewed the literature on manual chest percussion and THOMAs et al. [34] that on mechanical percussors. They concluded that there is a physiological 
rationale and a place for the use of percussion, but that the clinical evidence is inconclusive.

\section{High frequency chest wall oscillation and intrapulmonary percussive ventilation}

During HFCWO, positive pressure air pulses are applied to the chest wall, for example by means of an inflatable vest. It is hypothesized that increases in cough clearability may be due to an increase in mucus/airflow interaction and/or a shearing mechanism leading to a decrease in the viscoelasticity of mucus [35].

ArENs et al. [36] compared HFCWO with conventionai physiotherapy. Both regimens were equally safe and effective and it was suggested that the self-applied technique of HFCWO would provide an adequate alternative to conventional physiotherapy. This concurred with a review of the literature published in the same year [37]. KLUFT et al. [38] also compared HFCWO with conventional/standard chest physiotherapy and, as more sputum was expectorated during treatment when HFCWO was used, they also concluded that HFCWO was at least as effective.

Another form of HFCWO, the Hayek Oscillator, has been compared with the ACBT [39]. Significantly more sputum was expectorated when the regimen of the ACBT was used rather than the Hayek Oscillator.

IPV is the delivery of a pulsatile flow of gas to the lungs during inspiration. The volume of gas released with each pulse can be preset and the pulsation frequency adjusted. The patient initiates the flow of gas and during inspiration the pulsatile flow results in an internal percussion. Interruption of the inspiratory flow allows for passive expiration. It has been shown to be as effective as "standard" chest physiotherapy [40] and to assist mucus clearance and may be an alternative for some patients [41].

These devices are widely used in the USA and direct comparisons with other airway clearance regimens, more commonly used in other countries, are difficult to make.

\section{Incentive spirometry}

There is little evidence to support the use of IS in airway clearance $[42,43]$, but it is still used today [44]. It is a mechanical device which provides feedback at a preset inspiratory flow or volume of air, with the patient usually encouraged to hold their breath for $2-3 \mathrm{~s}$ at full inspiration. IS has not been compared with many of the airway clearance regimens, outlined below, and it is difficult to ascertain its effectiveness.

\section{Glossopharyngeal ("frog") breathing}

GPB is a technique useful in patients with a reduced vital capacity due to inspiratory muscle paralysis. It was first described by Dail [45] in 1951, when patients with poliomyelitis were observed to be gulping air into their lungs. It is a form of positive pressure ventilation produced by the patient's voluntary muscles, in which boluses of air are forced into the lungs.

To breathe in, a series of pumping strokes are produced by the action of the lips, tongue, soft palate, pharynx and larynx. Air is held in the chest by the larynx, which acts as a valve, as the mouth is opened for the next gulp.
Many patients with ineffective cough, for example tetraplegics or those with a neuromuscular disorder, can clear their airways more effectively by using GPB [46-48]. It is a technique which many physiotherapists and physical therapists are not familiar with today, but, if more widely used, patients in these groups would benefit.

\section{Active cycle of breathing techniques}

In 1968, THомPSON and THOMPson [13] published their work using forced expiration exercises to assist in the mobilization and clearance of secretions in patients with asthma. The year before, LANGLANDS [49] had demonstrated that the intrathoracic pressures generated by huffing were less than those generated by coughing, but it was 11 yrs before further work, using the technique of huffing or forced expirations, was published.

The ACBT $[50,51]$ is a cycle of techniques of breathing control (tidal breathing at the patient's own rate and depth, encouraging use of the lower chest with relaxation of the upper chest and shoulders), thoracic expansion exercises (deep breathing exercises emphasizing inspiration with or without a breath hold; expiration is quiet and relaxed) and the forced expiration technique (one or two huffs combined with periods of breathing control). Huffing to low lung volumes will assist in mobilizing and clearing the more peripherally situated secretions and, when secretions have reached the larger more proximal upper airways, a huff or cough from a high lung volume can be used to clear them.

The concept of the equal pressure point [52] explains the mechanism of the effectiveness of huffing in airway clearance. In addition, the viscosity of mucus is sheardependent [53], and the shear forces generated during huffing should reduce mucus viscosity. This together with the high flows generated during a forced expiratory manoeuvre would be expected to aid mucus clearance and the expectoration of sputum. There is also an inbuilt oscillatory movement of the airway walls during a forced expiratory manoeuvre and this, demonstrated by FREITAG et al. [54], should have an additional mechanical loosening, effect. The length of the huff and the force of contraction of the expiratory muscles are adapted to optimize expiratory flow.

The ACBT, when compared with "conventional" physiotherapy, has been shown to increase expectoration of sputum while reducing the length of time taken for treatment $[50,55]$. It has also been shown to be equally effective both with and without an assistant [27]. In patients with asthma, cystic fibrosis and chronic airflow limitation, there is no evidence of any increase in airflow obstruction $[27,56]$. There is no evidence of oxygen desaturation [31], and the ACBT is not further improved by use of the PEP mask [57], the Flutter $\AA$ [58], or mechanical percussion or oscillation devices $[39,59]$. There is evidence of an improvement in lung function (including forced expiratory volume in one second, forced vital capacity (FVC) and maximum expiratory flow at 25\% and $50 \%$ of FVC following the instigation of the ACBT [60]. The cycle is flexible and adapted to suit the needs of the individual. It can be used in any position according to the requirements of the patient, the sitting position or gravity assisted positions. 


\section{Autogenic drainage}

Autogenic drainage $[61,62]$ is breathing at different lung volumes and expiration is used to move the mucus. The aim is to maximize expiratory flow. Breathing at low lung volumes, in the individual patient, is used to mobilize more peripherally situated mucus. Breathing around the individual's tidal volume is said to collect mucus in the middle range, and, with breathing around high lung volumes, expectoration of secretions from the central airways is promoted. When sufficient mucus has reached the upper airways, it may be cleared by a cough. The regimen is adapted for the individual.

$\mathrm{AD}$ has been compared with "postural drainage and chest clapping" and it was concluded that AD was less likely to produce oxygen desaturation and may be better tolerated by patients while producing similar benefits [63]. One group has compared $\mathrm{AD}$ and the ACBT [64] and concluded that $\mathrm{AD}$ increased the rate of clearance of mucus, although there was no overall difference in the weight of sputum expectorated. There is debate, however, as to whether it was the ACBT which was used in the study in practice $[65,66]$.

DAVIDSON et al. [67] compared conventional percussion and drainage (PD) with AD and with PEP. They concluded that $\mathrm{AD}$ was more effective than PD in mobilizing sputum and that both AD and PEP probably offer advantages over PD.

$\mathrm{AD}$ has been modified by a group in Germany [14, 68 , 69]. The patient breathes around tidal volume while breath holding for 2-3 s at the end of each inspiration. Coughing is used to clear mucus mobilized to the upper airways.

\section{Flutter VRP1 R}

This device is pipe-shaped with a high-density stainless steel ball-bearing enclosed in a cone in the bowl of the "pipe". During expiration through the Flutter VRP1® (Flutter), the rise and fall of the ball and its movement along the surface of the cone creates a positive expiratory pressure and oscillatory vibration of the air within the airways. In addition, intermittent airflow accelerations are produced by the same ball movements. These three phenomena help to loosen secretions, which are mobilized to the central airways and cleared by deep exhalations through the device with the aid of subsequent coughing and/or huffing.

Konstan et al. [70] and, more recently, Homnick et al. [71] compared the Flutter with conventional physiotherapy. They concluded that the flutter regimen was more effective and preferred by patients. AmBrosino et al. [72] found the Flutter as effective as conventional physiotherapy. This is important evidence, but, when these studies were undertaken, many centres had, several years earlier, moved on from conventional physiotherapy to more effective regimens. This highlights the need for all researchers to communicate, collaborate when appropriate and acknowledge studies, internationally, demonstrating rigour.

PRYOR et al. [58] compared the Flutter with the ACBT [58], but the Flutter regimen used, which was current at the time of the study, did not include huffing and the ACBT was the more effective regimen. The forced expiratory manoeuvre of the huff, which is today usually included, should increase the effectiveness of the Flutter regimen and it is likely, in the short-term, that there is little difference between these two regimens. СНАтнам et al. [73] studied the use of the Flutter in patients following thoracotomy. They concluded that there was no additional benefit in either adding the Flutter to physiotherapy or substituting it for physiotherapy.

In the long-term (1 yr), the Flutter has been compared with PEP [74]. At 12 months, there were significant differences in the outcome measures of pulmonary function (FVC), hospital admissions and use of antibiotics. The authors concluded that the Flutter was not as effective as $\mathrm{PEP}$ in maintaining pulmonary function.

The effect of the Flutter and AD on sputum viscoelasticity have been compared [75]. The viscoelasticity was significantly lower following treatment with the Flutter. It is hypothesized that this reduction would improve mucociliary and cough clearability, but it is interesting to note that there were no differences between the regimens in the quantity of sputum expectorated during the treatment sessions.

\section{Positive expiratory pressure}

The PEP device consists of a face mask or mouthpiece and a one-way valve to which expiratory resistors can be attached [29]. A manometer is inserted into the system between the valve and the resistance to monitor the pressure. This should be $10-20 \mathrm{cmH}_{2} \mathrm{O}$ at mid-expiration. Tidal breathing, with a slightly active expiration, is used and lung volume is retained at a raised level by avoiding complete expiration. The forced expiration technique is used to clear the secretions that are mobilized. The duration and frequency of treatment are adapted for each individual.

PEP has been compared with "conventional" postural drainage $[76,77]$. In these studies, over a period of $1 \mathrm{yr}$, PEP was more effective than conventional physiotherapy in maintaining and improving lung function, and was the preferred regimen. Over a 2-yr-period, GASKIN et al. [78] found no significant differences between PEP and convenventional physiotherapy and concluded that the PEP mask was a valid alternative. PEP has also been used with effect as an adjunct to chest physiotherapy in patients following abdominal surgery [79]. The ACBT was compared with PEP [57] and found to be the more effective regimen.

High-pressure PEP is a modified form of PEP mask treatment. By using high pressures, $50-120 \mathrm{cmH}_{2} \mathrm{O}$, secretions may be mobilized more easily in patients with unstable airways [80].

Work is currently being undertaken on the use of PEP in people with intellectual impairment and with tracheomalacia. In the first group, it is probably effective as it requires little concentration on the half of the subject and, in the second, the positive expiratory pressure should help to stabilize the trachea during expiration.

\section{RC-Cornet $\mathrm{R}$}

The RC-Cornet $\mathbb{R}$ (Cornet) is a curved plastic tube containing a flexible latex-free valve-hose. During expiration through the Cornet, a positive expiratory pressure and oscillatory vibration of the air within the airways are generated. It can be used in any position as it is independent of gravitational forces. The flow, pressure and frequency of the oscillations can be adjusted to suit the individual patient. Secretions mobilized to the central airways are cleared by coughing or huffing. The Cornet has been compared with the Flutter and both were similar in the context of airway clearance [81]. 


\section{Exercise and airway clearance}

Exercise and airway clearance have been studied in subjects with cystic fibrosis. Exercise increases sputum production [82] but is not as effective as the ACBT [83]. The additional cardiovascular effects of exercise should be considered and it may be appropriate to exercise in addition to other airway clearance regimens [84] or as a substitute on some occasions [85].

\section{Humidification, hypertonic saline and dornase alfa}

Humidification has been shown to increase the clearance of sputum when used as an adjunct to physiotherapy in patients with bronchiectasis [86] and this is supported by a review of the literature [87].

Hypertonic saline [88] and dornase alfa [89] may also facilitate airway clearance when used in conjunction with an airway clearance technique.

\section{Discussion}

Many of the airway clearance regimens today include forced expiratory manoeuvres. "Forced expiratory manoeuvres are probably the most effective part of chest physiotherapy" [90]. For patients with chronic lung disease, there is insufficient evidence to prescribe either the regimen or the frequency with which it should be undertaken. If a regimen is used effectively and frequently enough to maintain or improve lung function, it may influence mortality in patients with cystic fibrosis [91] and probably in patients with bronchiectasis, but neither the optimal regimen nor the optimal frequency are known and both will vary among and within individuals. In some countries physiotherapists/physical therapists/respiratory therapists and other health professionals may be responsible for large numbers of patients in the context of airway clearance and the introduction of a device may facilitate practice.

The reasons patients give for "doing" chest physiotherapy include: "makes my chest clearer", "so I can do more", "makes my breathing easier", "stops me from coughing" [92]. It is important to note that neither "improves my lung function" nor "will increase my life span" were inferred. This highlights the differences between the expectations of the patient and the professional. The reasons for "not doing" chest physiotherapy included: "not enough time", "feel very well" and "too tired".

Taking into consideration both the patient's and the professional's views, an airway clearance regimen should be effective, efficient, easy to use and easy to teach, able to be undertaken independently or with an assistant, should improve lung function and should neither cause nor increase hypoxaemia nor be uncomfortable. It should also be flexible and adaptable to meet the changing needs of the individual patient.

\section{Conclusion}

There continues to be widespread debate as to which airway clearance regimen should be used and when. Part of the uncertainty regarding the effectiveness of airway clearance techniques may be due to the limitations of current measurement tools and to extrapolation of research outcomes to different subject groups. Many comparative studies have been undertaken in the short term. Long-term studies (1-4 yrs) are very much harder to set up and very expensive, but necessary to increase understanding of airway clearance. In undertaking studies in patients with chronic sputum production, patient preference should be one of the outcome measures, but some patients are likely to prefer the regimen with which they are most familiar.

If there were no clinically significant differences among the commonly used airway clearance techniques, this would be important information. If one or more of the techniques are proven to be significantly more effective and efficient, consideration would still have to be given to the technique to which a particular patient will adhere and, in today's world, to cost implications. The optimal airway clearance regimen, for which patient and when, presents an exciting research challenge.

This paper, like many others, demonstrates that the evidence to indicate to either patients or health professionals which airway clearance technique they should be using is not available. It would seem that individual preferences are leading the decision making process.

Acknowledgements. The author would like to thank U. Cegla, J. Chevaillier, C. Baker, M. Kelstrup, C. Ireland and B. Webber for providing some of the information for this paper.

\section{References}

1. Eid N, Buchheit J, Neuling M, Phelps H. Chest physiotherapy in review. Respir Care 1991; 36: 270-282.

2. Hardy KA. A review of airway clearance: new techniques, indications, and recommendations. Respir Care 1994; 39: 440-455.

3. Williams MT. Chest physiotherapy and cystic fibrosis. Why is the most effective form of treatment still unclear? Chest 1994; 106: 1872-1882.

4. Thomas J, Cook DJ, Brooks D. Chest physical therapy management of patients with cystic fibrosis: a metaanalysis. Am J Respir Crit Care Med 1995; 151: 846-850.

5. Butler SG, Sutherland RJ. Current airway clearance techniques. $N$ Z Med J 1998; 111: 183-186.

6. Prasad SA, Main E. Finding evidence to support airway clearance techniques in cystic fibrosis. Disabil Rehabil 1998; 20: 235-246.

7. Sigerist HE. A History of Medicine. Vol 1. Primitive and Archaic Medicine. New York, Oxford University Press, 1951; p. 481.

8. MacMahon C. Breathing and physical exercises for use in cases of wounds in the pleura, lung and diaphragm. Lancet 1915; 2: 769-770.

9. MacMahon C. Some cases of gunshot wounds and other affections of the chest treated by breathing and physical exercises. Lancet 1919; i: 697-699.

10. Ewart W. The treatment of bronchiectasis and of chronic bronchial affections by posture and by respiratory exercises. Lancet 1901; 2: 70-72.

11. Nelson HP. Postural drainage of the lungs. $B M J 1934 ; 2$ : 251-255.

12. Palmer KNV, Sellick BA. The prevention of postoperative pulmonary atelectasis. Lancet 1953; i: 164-168.

13. Thompson B, Thompson HT. Forced expiration exercises in asthma and their effect on FEV1. NZJ Physiother 1968; 3: 19-21. 
14. David A. Autogenic drainage - the German approach. In: Pryor JA, ed. Respiratory Care. Edinburgh, Churchill Livingstone, 1991: p. 65.

15. Lorin MI, Denning CR. Evaluation of postural drainage by measurement of sputum volume and consistency. Am J Phys Med 1971; 50: 215-219.

16. Steven MH, Pryor JA, Webber BA, Hodson ME. Physiotherapy versus cough alone in the treatment of cystic fibrosis. N ZJ Physiother 1992; 20: 31-37.

17. Bush A, Cole P, Hariri M, et al. Primary ciliary dyskinesia: diagnosis and standards of care. Eur Respir $J$ 1998; 12: 982-988.

18. Jenkins SC, Soutar SA, Loukota JM, Johnson LC, Moxham J. Physiotherapy after coronary artery surgery: are breathing exercises necessary? Thorax 1989; 44: 634639.

19. Bourn J, Jenkins S. Post-operative respiratory physiotherapy. Indications for treatment. Physiotherapy 1992; 78: $80-85$.

20. Jenkins SC, Soutar SA, Moxam J. The effects of posture on lung volumes in normal subjects and in patients preand post-coronary artery surgery. Physiotherapy 1988; 74: 492-496.

21. Dean E. Effect of body position on pulmonary function. Phys Ther 1985; 65: 613-618.

22. Ward RJ, Danziger F, Bonica JJ, Allen GD, Bowes J. An evaluation of postoperative respiratory maneuvers. Surg, Gynecol Obstet 1966; 123: 51-54.

23. Tucker B, Jenkins S. The effect of breathing exercises with body positioning on regional lung ventilation. Aust $J$ Physiother 1996; 42: 219-227.

24. Flower KA, Eden RI, Lomax L, Mann NM, Burgess J. New mechanical aid to physiotherapy in cystic fibrosis. BMJ 1979; 2: 630-631.

25. Campbell AH, O'Connell JM, Wilson F. The effect of chest physiotherapy upon the FEV1 in chronic bronchitis. Med J Aust 1975; 1: 33-35.

26. Wollmer P, Ursing K, Midgren B, Eriksson L. Inefficiency of chest percussion in the physical therapy of chronic bronchitis. Eur J Respir Dis 1985; 66: 233-239.

27. Pryor JA, Webber BA. An evaluation of the forced expiration technique as an adjunct to postural drainage. Physiotherapy 1979; 65: 304-307.

28. Gallon A. Evaluation of chest percussion in the treatment of patients with copious sputum production. Respir Med 1991; 85: 45-51.

29. Falk M, Kelstrup M, Andersen JB, et al. Improving the ketchup bottle method with positive expiratory pressure, PEP, in cystic fibrosis. Eur J Respir Dis 1984; 65: 423432.

30. McDonnell T, McNicholas WT, FitzGerald MX. Hypoxaemia during chest physiotherapy in patients with cystic fibrosis. Ir J Med Sci 1986; 155: 345-348.

31. Pryor JA, Webber BA, Hodson ME. Effect of chest physiotherapy on oxygen saturation in patients with cystic fibrosis. Thorax 1990; 45: 77.

32. Carr L, Pryor JA, Hodson ME. Self chest clapping. Patients' views and the effects on oxygen saturation. Physiotherapy 1995; 81: 753-757.

33. Gallon A. The use of percussion. Physiotherapy 1992; 78 : 85-89.

34. Thomas J, DeHueck A, Kleiner M, Newton J, Crowe J, Mahler S. To vibrate or not to vibrate: usefulness of the mechanical vibrator for clearing bronchial secretions. Physiother Can 1995; 47: 120-125.

35. Tomkiewicz RP, Biviji A, King M. Effects of oscillating air flow on the rheological properties and clearability of mucous gel simulants. Biorheology 1994; 31: 511-520.
36. Arens R, Gozal D, Omlin KJ, et al. Comparison of highfrequency chest compression and conventional chest physiotherapy in hospitalized patients with cystic fibrosis. Am J Respir Crit Care Med 1994; 150: 1154-1157.

37. Hansen LG, Warwick WJ, Hansen KL. Mucus transport mechanisms in relation to the effect of high frequency chest compression (HFCC) on mucus clearance. Pediatr Pulmonol 1994; 17: 113-118.

38. Kluft J, Beker L, Castagnino M, Gaiser J, Chaney H, Fink RJ. A comparison of bronchial drainage treatments in cystic fibrosis. Pediatr Pulmonol 1996; 22: 271-274.

39. Phillips GE, Pike S, Jaffe A, Bush A. Comparison of the active cycle of breathing techniques and external high frequency oscillation jacket for clearance of secretions in children with cystic fibrosis. Thorax 1998; 53 (Suppl. 4): A61.

40. Homnick DN, White F, de Castro C. Comparison of effects of an intrapulmonary percussive ventilator to standard aerosol and chest physiotherapy in treatment of cystic fibrosis. Pediatr Pulmonol 1995; 20: 50-55.

41. Langenderfer B. Alternatives to percussion and postural drainage. A review of mucus clearance therapies: percussion and postural drainage, autogenic drainage, positive expiratory pressure, flutter valve, intrapulmonary percussive ventilation, and high-frequency chest compression with the ThAIRapy vest. J Card Pulm Rehabil 1998; 18 : 283-289.

42. Hall JC, Tarala R, Harris J, Tapper J, Christiansen K. Incentive spirometry versus routine chest physiotherapy for prevention of pulmonary complications after abdominal surgery. Lancet 1991; 337: 953-956.

43. Gosselink R, Schrever K, Cops P, et al. Incentive spirometry does not enhance recovery after thoracic surgery. Crit Care Med 1999 (in press).

44. Wattie J. Incentive spirometry following coronary artery bypass surgery. Physiotherapy 1998; 84: 508-514.

45. Dail CW. "Glossopharyngeal breathing" by paralyzed patients. Calif Med 1951; 75: 217-218.

46. Dail CW, Affeldt JE, Collier CR. Clinical aspects of glossopharyngeal breathing. JAMA 1955; 158: 445-449.

47. Alvarez SE, Peterson M, Lunsford BR. Respiratory treatment of the adult patient with spinal cord injury. Phys Ther 1981; 61: 1737-1745.

48. Webber BA, Higgens JM. Glossopharyngeal ("Frog") Breathing - What, When and How? 1999; 43 min. (Video, available by telephoning 44 1494725724).

49. Langlands J. The dynamics of cough in health and in chronic bronchitis. Thorax 1967; 22: 88-96.

50. Pryor JA, Webber BA, Hodson ME, Batten JC. Evaluation of the forced expiration technique as an adjunct to postural drainage in treatment of cystic fibrosis. $B M J$ 1979; 2: 417-418.

51. Webber BA, Pryor JA. Physiotherapy techniques. In: Pryor JA, Webber BA, eds. Physiotherapy for Respiratory and Cardiac Problems. 2nd Edn. Edinburgh, Churchill Livingstone, 1998; pp. 137-155.

52. West JB. Pulmonary Pathophysiology. The Essentials. 5th Edn. Baltimore, Williams \& Wilkins 1997; pp. 7-9.

53. Lopez-Vidriero MT, Reid L. Bronchial mucus in health and disease. B Med Bull 1978; 34: 63-74.

54. Freitag L, Bremme J, Schroer M. High frequency oscillation for respiratory physiotherapy. Br J Anaesth 1989; 63: $44 \mathrm{~S}-46 \mathrm{~S}$

55. Wilson GE, Baldwin AL, Walshaw MJ. A comparison of traditional chest physiotherapy with the active cycle of breathing in patients with chronic suppurative lung disease. Eur Respir J 1995; 8: Suppl. 19, 171S.

56. Pryor JA, Wiggins J, Webber BA, Geddes DM. Oral high 
frequency oscillation (OHFO) as an aid to physiotherapy in chronic bronchitis with airflow limitation. Thorax 1989; 44: 350P

57. Hofmeyr JL, Webber BA, Hodson ME. Evaluation of positive expiratory pressure as an adjunct to chest physiotherapy in the treatment of cystic fibrosis. Thorax 1986; 41: 951-954.

58. Pryor JA, Webber BA, Hodson ME, Warner JO. The Flutter VRP1 as an adjunct to chest physiotherapy in cystic fibrosis. Respir Med 1994; 88: 677-681.

59. Pryor JA, Parker RA, Webber BA. A comparison of mechanical and manual percussion as adjuncts to postural drainage in the treatment of cystic fibrosis in adolescents and adults Physiotherapy 1981; 67: 140-141.

60. Webber BA, Hofmeyr JL Morgan MDL Hodson ME. Effects of postural drainage, incorporating the forced expiration technique, on pulmonary function in cystic fibrosis. Br J Dis Chest 1986; 80: 353-359.

61. Schöni MH. Autogenic drainage: a modern approach to physiotherapy in cystic fibrosis. $J R$ Soc Med 1989; 82 : Suppl. 16,32-37.

62. Chevaillier J. Autogenic drainage (AD). In: Physiotherapy in the Treatment of Cystic Fibrosis (CF). International Physiotherapy Group for Cystic Fibrosis (IPG/ CF). 1995; pp. 9-12.

63. Giles DR, Wagener JS, Accurso FJ, Butler-Simon N Short-term effects of postural drainage with clapping versus autogenic drainage on oxygen saturation and sputum recovery in patients with cystic fibrosis. Chest 1995 108: 952-954.

64. Miller S, Hall DO, Clayton CB, Nelson R. Chest physiotherapy in cystic fibrosis: a comparative study of autogenic drainage and the active cycle of breathing techniques with postural drainage. Thorax 1995; 50: 165-169.

65. Webber BA. Chest physiotherapy in cystic fibrosis. Thorax 1995; 50: 1123.

66. Nelson R, Miller S, Hall D, Clayton B. Chest physiotherapy in cystic fibrosis. Thorax 1995; 50: 1123-1124.

67. Davidson AGF, Mcllwaine PM, Wong LTK, Nakielna EM, Pirie GE. Physiotherapy in cystic fibrosis: a comparative trial of positive expiratory pressure, autogenic drainage and conventional percussion and drainage techniques. Pediatr Pulmonol 1998; Suppl. 2, 132.

68. Lindemann H, Boldt A, Kieselmann R. Autogenic drainage: efficacy of a simplified method. Acta Univ Carol [Med] (Praha) 1990; 36: 210-212.

69. Kieselmann R. Modified AD (M AD). In: Physiotherapy in the Treatment of Cystic Fibrosis (CF). International Physiotherapy Group for Cystic Fibrosis (IPG/CF), 1995; pp. 13-14.

70. Konstan MW, Stern RC, Doershuk CF. Efficacy of the Flutter device for airway mucus clearance in patients with cystic fibrosis. J Pediatr 1994; 124: 689-693.

71. Homnick DN, Anderson K, Marks JH. Comparison of the flutter device to standard chest physiotherapy in hospitalized patients with cystic fibrosis: a pilot study. Chest 1998; 114: 993-997.

72. Ambrosino N, Callegari G, Galloni C, Brega S, Pinna G. Clinical evaluation of oscillating positive expiratory pressure for enhancing expectoration in diseases other than cystic fibrosis. Monaldi Arch Chest Dis 1995; 50: 269 275.

73. Chatham K, Marshall C, Campbell IA, Prescott RJ. The Flutter VRP1 device for post-thorocotomy patients. Physiotherapy 1993; 79: 95-98.

74. Mcllwaine PM, Wong LTK, Peacock D, Davidson AGF. "Flutter versus PEP": a long-term comparative trial of positive expiratory pressure (PEP) versus oscillating posi- tive expiratory pressure (Flutter) physiotherapy techniques. Pediatr Pulmonol 1997; Suppl. 14, 299.

75. App EM, Kieselmann R, Reinhardt D, et al. Sputum rheology changes in cystic fibrosis lung disease following two different types of physiotherapy. Flutter versus autogenic drainage. Chest 1998; 114: 171-177.

76. Christensen EF, Nedergaard T, Dahl R. Long-term treatment of chronic bronchitis with positive expiratory pressure mask and chest physiotherapy. Chest 1990; 97 : 645-650.

77. Mcllwaine PM, Wong LT, Peacock D, Davidson AGF. Long-term comparative trial of conventional postural drainage and percussion versus positive expiratory pressure physiotherapy in the treatment of cystic fibrosis. $J$ Pediatr 1997; 131: 570-574

78. Gaskin L, Corey M, Shin J, Reisman JJ, Thomas J, Tullis DE. Long term trial of conventional postural drainage and percussion versus positive expiratory pressure. Pediatr Pulmonol 1998; Suppl. 17, 345.

79. Campbell T, Ferguson N, McKinlay RGC. The use of a simple self-administered method of positive expiratory pressure (PEP) in chest physiotherapy after abdominal surgery. Physiotherapy 1986; 72: 498-500.

80. Oberwaldner B, Evans JC, Zach MS. Forced expirations against a variable resistance: a new chest physiotherapy method in cystic hbrosis. Pediatr Pulmonol 1986; 2: 358367.

81. Cegla UH, Bautz M, Fröde G, Werner Th. Physiotherapie bei Patienten mit COAD und tracheobronchialer Instabilität - vergleich zweier oszillierender PEP-systeme (RC-Cornet $\mathbb{R}$, VRP1 Desitin) Pneumologie 1997; 51: 129-136.

82. Baldwin DR, Hill AL, Peckham DG, Knox AJ. Effect of addition of exercise to chest physiotherapy on sputum expectoration and lung function in adults with cystic fibrosis. Respir Med 1994; 88: 49-53.

83. Salh W, Bilton D, Dodd M, Webb AK. Effect of exercise and physiotherapy in aiding sputum expectoration in adults with cystic fibrosis. Thorax 1989; 44: 1006-1008.

84. Bilton D, Dodd ME, Abbot JV, Webb AK. The benefits of exercise combined with physiotherapy in the treatment of adults with cystic fibrosis. Respir Med 1992; 86: 507511.

85. Cerny FJ. Relative effects of bronchial drainage and exercise for in-hospital care of patients with cystic fibrosis. Physical Therapy 1989; 69: 633-639.

86. Conway JH, Fleming JS, Perring S, Holgate ST. Humidification as an adjunct to chest physiotherapy in aiding tracheo-bronchial clearance in patients with bronchiectasis. Respir Med 1992; 86: 109-114.

87. Conway JH. The effects of humidification for patients with chronic airways disease. Physiotherapy 1992; 78: 97-101.

88. Eng PA, Morton J, Douglass JA, Riedler J, Wilson J, Robertson CF. Short-term efficacy of ultrasonically nebulised hypertonic saline in cystic fibrosis. Pediatr Pulmonol 1996; 21: 77-83.

89. Hodson ME, Shah PL. DNase trials in cystic fibrosis. Eur Respir J 1995; 8: 1786-1791.

90. van der Schans CP. Forced expiratory manoeuvres to increase transport of bronchial mucus: a mechanistic approach. Monaldi Arch Chest Dis 1997; 52: 367-370.

91. Kerem E, Reisman J, Corey M, Canny GJ, Levison H. Prediction of mortality in patients with cystic fibrosis. $N$ Engl J Med 1992; 326: 1187-1191.

92. Carr L, Smith RE, Pryor JA, Partridge C. Cystic fibrosis patients' views and beliefs about chest clearance and exercise - a pilot study. Physiotherapy 1996; 82: 621-627. 